\title{
Evaluation of Mucosal and Systemic Vaccine Responses by Cyclic di-GMP (CDG)-adjuvanted Protein Subunit Vaccines
}

Samira Mansouri and Lei Jin*

\author{
Division of Pulmonary, Critical Care, and Sleep Medicine, Department of Medicine, University of Florida, \\ Gainesville, FL, USA \\ *For correspondence: lei.jin@medicine.ufl.edu
}

\begin{abstract}
[Abstract] Intranasal administration of vaccine adjuvants directly deliver therapeutic agents to the lungs to induce potent lung mucosal immune responses. Cyclic di-GMP (CDG) is a promising mucosal vaccine adjuvant candidate capable of inducing protective immunity. This protocol describes an in vivo approach to induce and detect mucosal (lung) and systemic (blood and spleen) vaccine adjuvant responses of CDG. This protocol also includes the methods to detect both humoral and cellular immune responses of CDG adjuvant. Last, this protocol can be used to study other cyclic dinucleotides as mucosal vaccine adjuvants.
\end{abstract}

Keywords: Cyclic dinucleotides, Mucosal vaccine adjuvant, Intranasal immunization, Humoral and cellular vaccine responses, Ex vivo recall assay

[Background] Cyclic diguanylate monophosphate (CDG) is part of a new class of vaccine adjuvants called cyclic dinucleotides currently being used in clinical trials for the treatment of cancer and infectious diseases. In vitro and in vivo administration of CDG can induce strong immune responses by engaging the STING pathway to induce production of type I interferon and TNFa (McWhirter et al., 2009; Blaauboer et al., 2014). As a potential mucosal vaccine adjuvant, CDG is well known to induce protective immunity against bacterial pathogens by producing strong antibody and Th1/Th2/Th17 responses in the lung (Ebensen et al., 2007; Yan et al., 2009; Madhun et al., 2011). Mechanistically, this mucosal adjuvant acts through the lung resident dendritic cells (Blaauboer et al., 2014; Mansouri et al., 2019). To date, the cellular and molecular mechanisms of CDG have been mainly characterized by in vitro experiments with murine and human cultured cells. In vitro studies often use transfection reagents to administer CDG into cells. As CDG has two phosphate groups preventing it from directly passing through the cell membrane, the method of transfection may be artificial. Interestingly, CDG was found to be taken up by cells via pinocytosis in vivo (Blaauboer et al., 2015). This protocol describes a more physiological relevant approach to studying the adjuvant effect of CDG in vivo through intranasal immunization.

\section{Materials and Reagents}

1. BD Instyle Autoguard BC Shielded IV Catheter (BD, catalog number: 381423)

2. $1.5 \mathrm{ml}$ Eppendorf tubes (USA Scientific, catalog number: 1615-5510)

3. Serum Collection Micro Tube $1.1 \mathrm{ml}$ Z-Gel (Sarstedt, catalog number: 41.1500.005) 
4. ELISA Assay Plate (Corning, catalog number: 3690 )

5. $70 \mu \mathrm{m}$ mesh (Fisher Scientific, catalog number: 22363548)

6. 96-well round bottom culture plate (Corning, catalog number: 3799 )

7. Styrofoam board (we use the tops of ice boxes-there is no catalog number)

8. BD PrecisionGlide ${ }^{\mathrm{TM}}$ Needle $25 \mathrm{G} \times 5 / 8$ (BD, catalog number: 305122)

9. $1 \mathrm{ml}$ Syringes (BD, catalog number: 309597$)$

10. $50 \mathrm{ml}$ tubes (Corning, catalog number: 430828)

11. Mice C57BL/6 male and female (age 8-16 weeks, males, and females)

12. PspA (family 1, clade 2) (BEI Resources, catalog number: NR-33178)

13. Anti-mouse IgG-HRP (Southern Biotech, catalog number: 1030-05)

14. Anti-mouse IgG1-HRP (Southern Biotech, catalog number: 1070-05)

15. Anti-mouse IgG2C-HRP (Southern Biotech, catalog number: 1079-05)

16. Anti-mouse IgA-HRP (Southern Biotech, catalog number: 1040-05)

17. H1N1 influenza A nucleoprotein (Sino Biological, catalog number: 11675-v08B)

18. CDG (Invivogen, catalog number: vac-cdg)

19. Ovalbumin EndoFit ${ }^{\mathrm{TM}}$ (InvivoGen, catalog number: vac-pova)

20. Endotoxin-free physiological water (Fisher Scientific, catalog number: BP2470-1)

21. Endotoxin-free PBS (Enzo, catalog number: ALX-505-007-L010)

22. Isoflurane (Patterson Veterinary, catalog number: NDC 14043-70405)

23. 10x PBS (Fisher Scientific, catalog number: BP399-1)

24. $70 \%$ Ethanol

25. Tween ${ }^{\circledR} 20$ (Fisher Scientific, catalog number: BP337-100)

26. ELISA Assay Diluent (Invitrogen, catalog number: 00-4202-43)

27. ELISA Coating Buffer (Invitrogen, catalog number: 50-112-8923)

28. 1x TMB Solution (Invitrogen, catalog number: 00-4201-56)

29. ELISA Stop Solution (Invitrogen, catalog number: SS04)

30. RPMI (Invitrogen, catalog number:11875-093)

31. DMEM (Invitrogen, catalog number: 11965118)

32. Fetal bovine serum (ATLANTA Biological, catalog number: $\mathrm{S} 11150 \mathrm{H}$ )

33. ACK Lysis buffer (Invitrogen, catalog number: A10492-01)

34. $100 \mathrm{mM}$ sodium pyruvate (Gibco, catalog number: $11360-070$ )

35. 1 M HEPES (Gibco, catalog number:15630-80)

36. 2-Mercaptoethanol (Sigma, catalog number: M6250-10ML)

37. 100x Pen/Strep (Gibco, catalog number:15140-122)

38. DNasel (Roche, catalog number: 10104159001)

39. Liberase TM (Roche, catalog number: 05401127 001)

40. eBiosciences ${ }^{\mathrm{TM}}$ Ready-Set-Go IFNy, IL-17A, IL-5 and IL-13 ELISA kits (Fishersci, catalog numbers: 50-173-19, 50-112-8965, 50-172-08, 50-172-61)

41. Lung digestion buffer (see Recipes) 
42. $10 \%$ Culture Media (see Recipes)

43. ELISA washing buffer (see Recipes)

\section{Equipment}

1. E-Z Anesthesia system (Euthanex Corp)

2. Flowmeter (comes with $E-Z$ Anesthesia)

3. Vaporizer (comes with E-Z Anesthesia)

4. Fisher Scientific Digital Vortex Mixer (Fisher Scientific, catalog number: 02-215-370)

5. Forceps (not necessary, any dissecting forceps)

6. Scissors (not necessary, any dissecting scissors)

7. Thermo Scientific Revco Rel450A Refrigerator (Thermo Scientific, catalog number: DISCONTINUED)

8. $-20^{\circ} \mathrm{C}$ freezer (VWR, catalog number: 10819-408)

9. $-80^{\circ} \mathrm{C}$ freezer (Thermo Scientific, catalog number: RLE30086A)

10. $\mathrm{xMark}^{\mathrm{TM}}$ Microplate Absorbance Spectrophotometer (BIORAD, catalog number: 168-1150)

11. Heracell 150i $\mathrm{CO}_{2}$ incubator (Thermo Fisher, catalog number: 50116047)

\section{Procedure}

A. Vaccine preparation

1. Preparation of CDG

a. Prepare sterile CDG stock $(2 \mathrm{mg} / \mathrm{ml})$ with endotoxin-free physiological water in a $1.5 \mathrm{ml}$ sterile Eppendorf tube.

b. Mix the solution by pipetting up and down.

c. Store at $-80^{\circ} \mathrm{C}$. The $\mathrm{CDG}$ stock retains its activity for at least 3 years in our lab.

2. Preparation of antigens

a. Prepare sterile stock antigen (PspA, OVA or H1N1 NP) solution $(1 \mathrm{mg} / \mathrm{ml})$ with endotoxinfree PBS.

b. Mix the solution by pipetting up and down.

c. Store at $-80^{\circ} \mathrm{C}$. The protein antigen stocks are stable for at least 3 years in our lab.

B. Intranasal vaccine administration

1. At Day 0 , freshly prepare a suspension containing $5 \mu \mathrm{g}$ of CDG and $2 \mu \mathrm{g}$ of antigen per mouse in endotoxin-free 1x PBS for experimental samples.

2. At Day 0 , freshly prepare a suspension containing $2 \mu \mathrm{g}$ of antigen per mouse in endotoxin-free PBS for control samples.

3. Anesthetize the mouse by placing in the isoflurane chamber. 

a. To use the machine, turn on the supply gas and have the flowmeter between 500-1,000 $\mathrm{ml} / \mathrm{min}$.
b. Turn on vaporizer to $5 \%$.
c. Place the mouse in the chamber and seal the top.
d. Wait until the mouse is anesthetized.

4. Remove the mouse from the chamber and hold the mouse in your hand by the dorsal skin so that the head is up.

5. Administer $30 \mu \mathrm{l}$ of the vaccine solution into animal's nostril. Let the animal breathes in the vaccine solution.

6. Wait for 14 days before administrating a second immunization (Total 2 immunizations).

C. Collection of sera to measure antigen-specific antibodies in the blood

1. CDG-induced serum antibodies can be detected at 2-week, 1-month, 3-month, and 6-month after the last immunization.

2. Collect blood from the tail of each mouse.
a. Cut as close to the bottom of the mouse tail.
b. Collect around 50-100 $\mu \mathrm{l}$ of blood and place in a serum collection tube.
c. Spin samples down at $600 \times g$ at RT for $10 \mathrm{~min}$.
d. Collect the supernatant and store samples at $-20^{\circ} \mathrm{C}$.

D. Harvest of bronchoalveolar fluid (BALF) to measure antigen-specific antibodies in the lung

1. CDG-induced BALF antibodies can be detected at 2-week, 1-month, 3-month, and 6-month after the last immunization.

2. Sacrifice mouse with $\mathrm{CO}_{2}$.

3. Clean the mouse with $70 \%$ ethanol.

4. Place the mouse on a styrofoam board and restrain the arms and legs with needles.

5. Remove the skin around the neck to expose the thoracic cage and neck.

6. Gently remove the muscles around the neck with forceps to expose the trachea.

7. Using scissors, make a small cut on the surface of the trachea.

8. Load a $1 \mathrm{ml}$ syringe with $0.8 \mathrm{ml}$ of $1 \times$ PBS.

9. Attach a BD Instyle Autoguard BC Shielded IV Catheter to the $0.8 \mathrm{ml}$ syringe and insert into the trachea.

10. Slowly inject and recover the $1 \times$ PBS into a $1.5 \mathrm{ml}$ Eppendorf tube, and place on ice.

11. Spin down samples at $350 \times g$ at $4{ }^{\circ} \mathrm{C}$ for $5 \mathrm{~min}$.

12. Transfer the supernatant to a new $1.5 \mathrm{ml}$ Eppendorf tube and place on ice.

13. Store samples at $-20^{\circ} \mathrm{C}$. 
E. Detection of antigen-specific $\lg G$, IgG1, IgG2C (C57BL/6 mice) or IgG2A (BALB/c mice) and IgA production in the serum and BALF

1. Coat an ELISA assay plate using $1 \mu \mathrm{g} / \mathrm{ml}$ of antigen (PspA, H1N1 NP or OVA) in coating buffer.

a. Add $50 \mu \mathrm{l}$ per well.

b. Keep plate at $4{ }^{\circ} \mathrm{C}$ overnight.

2. Wash the plate 5 times using wash buffer.

3. Add $100 \mu \mathrm{l}$ of blocking buffer to each well and leave at room temperature for $1 \mathrm{~h}$.

4. After blocking is done, wash the plate 5 times with wash buffer.

5. Dilute sera samples starting with 1:5,000 in blocking buffer at 2-fold dilutions for 4 dilutions.

6. Dilute the BALF samples starting with 1:100 in blocking buffer at 2-fold dilutions for 4 dilutions.

7. Add $50 \mu \mathrm{l}$ of each serial dilution to the respective wells.

8. Keep plate at $4{ }^{\circ} \mathrm{C}$ overnight.

9. Wash the plate 5 times using wash buffer.

10. Add secondary antibodies conjugated to HRP to each well and leave at room temperature for 2 h.

11. Wash the plate 5 times using wash buffer.

12. Add $50 \mu \mathrm{ITMB}$ solution to each well and incubate for $15 \mathrm{~min}$.

13. Add $50 \mu \mathrm{l}$ stop solution.

14. Read samples at $450 \mathrm{~nm}$ on a plate reader.

F. Recall assay to measure antigen-specific $T$ cell responses in the lung (mucosal responses, carry out under sterile conditions)

1. Harvest the lung at 2-week, 1-month, 3-month, and 6-month after the last immunization.

a. To isolate lung cells, sacrifice immunized mice with $\mathrm{CO}_{2}$.

b. Clean the mouse with $70 \%$ ethanol.

c. Open the rib cage to expose the heart and lungs.

d. Cut the aorta above the liver.

e. Using sterile $1 \times$ PBS, inject $10 \mathrm{ml}$ of cold $1 \times$ PBS into the left ventricle to perfuse the lungs. Perfused lung should be white.

f. Transfer the lungs into $1.5 \mathrm{ml}$ Eppendorf tubes that contain $500 \mu \mathrm{l}$ of ice-cold $1 \times$ PBS to wash the lungs.

g. Add the lungs to $1.5 \mathrm{ml}$ Eppendorf tubes that contain $1 \mathrm{ml}$ digestion buffer and keep at $37^{\circ} \mathrm{C}$ for $1.5 \mathrm{~h}$. The digesting buffer has been prewarmed to $37^{\circ} \mathrm{C}$.

2. Make a single cell suspension after digestion

a. Use a $1 \mathrm{ml}$ syringe plunger to press the digested lung tissue through a $70 \mu \mathrm{m}$ mesh with sterile RMPI and into a sterile $50 \mathrm{ml}$ tube.

b. Spin the samples down at $350 \times g$ for $5 \mathrm{~min}$ at $4{ }^{\circ} \mathrm{C}$.

c. Decant the supernatant.

d. Add $1 \mathrm{ml}$ of ice-cold sterile ACK lysis buffer to the pellet. 
i. Disaggregate the cell pellet, re-suspend and transfer the cells to a $1.5 \mathrm{ml}$ Eppendorf tube and invert for $2 \mathrm{~min}$ at RT.

ii. Spin tubes down at $350 \times g$ for 5 min at $4{ }^{\circ} \mathrm{C}$.

iii. Decant supernatant.

e. Disaggregate the cell pellet and re-suspend cells in $1 \mathrm{ml}$ of sterile RPMI and count cells.

Lung harvested from one 8 16 weeks old WT C57BL/6 mouse typically yield $\sim 75$ million total cells with a cell viability $>90 \%$.

f. Spin samples down at $350 \times \mathrm{g}$ for $5 \mathrm{~min}$.

g. Re-suspend in $10 \%$ Culture Media to a concentration of 50-60 million cells $/ \mathrm{ml}$.

3. Set up the ex vivo recall assay.
a. In a 96-well round bottom tissue culture plate, $200 \mu$ l of lung cells are seeded.
b. Add $1 \mu \mathrm{g}$ of antigen into each well. The final antigen concentration is $5 \mu \mathrm{g} / \mathrm{ml}$.
c. Cells are cultured at $37^{\circ} \mathrm{C}$ and $5 \% \mathrm{CO}_{2}$ for 4 days.

4. Collect all supernatant to measure IFNy, IL-5/IL-13, IL-17A cytokine production using ELISA kits from eBioscience ${ }^{\mathrm{TM}}$.
a. Transfer samples from each well to Eppendorf tubes and spin down at $350 \times \mathrm{g}$ for $5 \mathrm{~min}$.
b. Transfer supernatant to new Eppendorf tubes.
c. Store at $-20^{\circ} \mathrm{C}$.

G. Recall assay to measure antigen-specific $T$ cell responses in the spleen (systemic responses, carry out under sterile conditions)

1. Make a single cell suspension

a. Harvest the spleen at 2-week, 1-month, 3-month, and 6-month after the last immunization.

b. Use a $1 \mathrm{ml}$ syringe plunger to press the smashed spleen tissue through a $70 \mu \mathrm{m}$ mesh with sterile ice-cold RPMI with $2 \% \mathrm{FCS} / 1 \mathrm{mM}$ EDTA into a sterile $50 \mathrm{ml}$ tube.

c. Spin the samples down at $350 \times g$ for 5 min at $4{ }^{\circ} \mathrm{C}$.

d. Carefully aspirated the supernatant.

e. Add ice-cold sterile ACK lysis buffer $(5 \mathrm{ml})$ to the pellet.

i. Disaggregate the cell pellet, re-suspend cells and left at RT for $5 \mathrm{~min}$.

ii. Add $20 \mathrm{ml}$ ice-cold RPMI/2\% FCS/1 mM EDTA to spin tubes down at $350 \times \mathrm{g}$ for $5 \mathrm{~min}$ at $4{ }^{\circ} \mathrm{C}$.

iii. Decant supernatant.

f. Add $1 \mathrm{ml}$ of sterile ice-cold RPMI/2\% FCS/ $1 \mathrm{mM}$ EDTA.

g. Disaggregate the cell pellet and resuspend cells.

h. Transfer the cells to $1.5 \mathrm{ml}$ Eppendorf tubes and count cells.

i. Spin samples down at $350 \times g$ for $5 \min 4{ }^{\circ} \mathrm{C}$.

j. Re-suspend in 10\% Culture Media to a concentration of 50-60 million cells $/ \mathrm{ml}$.

2. Set up the ex-vivo activation system

a. In a 96-well round bottom tissue culture plate, $200 \mu$ l of spleen cells are seeded. 
b. Add $1 \mu \mathrm{g}$ of antigen into each well. The final antigen concentration is $5 \mu \mathrm{g} / \mathrm{ml}$.

c. Cells are cultured at $37^{\circ} \mathrm{C}$ and $5 \% \mathrm{CO}_{2}$ for 4 days.

3. Collect all supernatant to measure IFNY, IL-5/IL-13, IL-17A cytokine production using ELISA kits from eBioscience ${ }^{\mathrm{TM}}$.
a. Transfer samples from each well to Eppendorf tubes and spin down at $350 \times \mathrm{g}$ for $5 \mathrm{~min}$.
b. Transfer supernatant to new Eppendorf tubes.
c. Store at $-20^{\circ} \mathrm{C}$.

\section{$\underline{\text { Recipes }}$}

1. Lung digestion buffer

a. Prepare a sterile $100 \mathrm{mg} / \mathrm{ml}$ solution of DNase I

Weigh $100 \mathrm{mg}$ of DNase I and dissolve it in $1 \mathrm{ml}$ of sterile water

Vortex and distribute as $50 \mu \mathrm{l}$ aliquots into $1.5 \mathrm{ml}$ Eppendorf tubes

Store at $-20^{\circ} \mathrm{C}$

b. Prepare a sterile $2.5 \mathrm{mg} / \mathrm{ml}$ solution of Liberase TM

Weigh $5 \mathrm{mg}$ of Liberase TM and dissolve it in $2 \mathrm{ml}$ of sterile water

Vortex and distribute as $200 \mu \mathrm{l}$ aliquots into $1.5 \mathrm{ml}$ Eppendorf tubes

Store at $-20^{\circ} \mathrm{C}$

c. Freshly prepare digestion buffer for each mouse containing $200 \mu \mathrm{g}$ DNase I and $25 \mu \mathrm{g}$

Liberase TM in $1 \mathrm{ml}$ of RPMI. Pre-warm to $37^{\circ} \mathrm{C}$ before use

2. $10 \%$ Culture Media

FBS $50 \mathrm{ml}$

100x $100 \mathrm{mM}$ sodium pyruvate $5 \mathrm{ml}$

100x $1 \mathrm{M}$ HEPES $5 \mathrm{ml}$

100x Pen/Strep $5 \mathrm{ml}$

2-Mercaptoethanol $2 \mu \mathrm{l}$

DMEM $435 \mathrm{ml}$

3. ELISA wash buffer

Add $0.1 \%$ Tween $^{\circledR} 20$ to $1 \times$ PBS

Thoroughly mix

\section{Acknowledgments}

This protocol was adapted from previously published work (Blaauboer et al., 2014 and 2015; Mansouri et al., 2019). The work was supported by R01Al110606 and R21Al125999 to LJ. 


\section{Competing interests}

The authors declare no conflict of interests.

\section{Ethics}

Mice were housed and bred in the Animal Research Facility at the University of Florida. All experiments with mice were performed by the regulations and approval of the Institutional Animal Care and Use Committee from the University of Florida (Protocol number 201609362, 05/09/2016 05/08/2019).

\section{References}

1. Blaauboer, S. M., Gabrielle, V. D. and Jin, L. (2014). MPYS/STING-mediated TNF-a, not type I IFN, is essential for the mucosal adjuvant activity of $\left(3^{\prime}-5^{\prime}\right)$-cyclic-di-guanosine-monophosphate in vivo. J Immunol 192(1): 492-502.

2. Blaauboer, S. M., Mansouri, S., Tucker, H. R., Wang, H. L., Gabrielle, V. D. and Jin, L. (2015). The mucosal adjuvant cyclic di-GMP enhances antigen uptake and selectively activates pinocytosis-efficient cells in vivo. Elife 4: e06670.

3. Ebensen, T., Schulze, K., Riese, P., Morr, M. and Guzman, C. A. (2007). The bacterial second messenger cdiGMP exhibits promising activity as a mucosal adjuvant. Clin Vaccine Immunol 14(8): 952-958.

4. Madhun, A. S., Haaheim, L. R., Nostbakken, J. K., Ebensen, T., Chichester, J., Yusibov, V., Guzman, C. A. and Cox, R. J. (2011). Intranasal c-di-GMP-adjuvanted plant-derived H5 influenza vaccine induces multifunctional Th1 $\mathrm{CD}^{+}$cells and strong mucosal and systemic antibody responses in mice. Vaccine 29(31): 4973-4982.

5. Mansouri, S., Patel, S., Katikaneni, D. S., Blaauboer, S. M., Wang, W., Schattgen, S., Fitzgerald, K. and Jin, L. (2019). Immature lung TNFR2- conventional DC 2 subpopulation activates moDCs to promote cyclic di-GMP mucosal adjuvant responses in vivo. Mucosal Immunol 12(1): 277289.

6. McWhirter, S. M., Barbalat, R., Monroe, K. M., Fontana, M. F., Hyodo, M., Joncker, N. T., Ishii, K. J., Akira, S., Colonna, M., Chen, Z. J., Fitzgerald, K. A., Hayakawa, Y. and Vance, R. E. (2009). A host type I interferon response is induced by cytosolic sensing of the bacterial second messenger cyclic-di-GMP. J Exp Med 206(9): 1899-1911.

7. Yan, H., KuoLee, R., Tram, K., Quu, H., Zhang, J., Patel, G. B. and Chen, W. (2009). 3',5'-Cyclic diguanylic acid elicits mucosal immunity against bacterial infection. Biochem Biophys Res Commun 387(3): 581-584. 